\title{
Study of correlation of ultrasonography with surgical evaluation of adnexal masses: a prospective study
}

\author{
Urmila Tripathi, Geetanjali Munda*
}

Department of Obstetrics and Gynecology, Gajra Raja Medical College, Gwalior, Madhya Pradesh, India

Received: 23 July 2018

Accepted: 28 August 2018

\section{*Correspondence:}

Dr. Geetanjali Munda,

E-mail: geetanjali.munda@gmail.com

Copyright: (C) the author(s), publisher and licensee Medip Academy. This is an open-access article distributed under the terms of the Creative Commons Attribution Non-Commercial License, which permits unrestricted non-commercial use, distribution, and reproduction in any medium, provided the original work is properly cited.

\begin{abstract}
Background: Adnexal masses are one of the most common pathologies among women of all age groups. Ovarian tumors, alone, represent two thirds of these cases. Malignant ovarian tumors are the fourth most common cause of death in women. Accurate diagnosis is required foremost for proper treatment and management of the patients.

Methods: A prospective study done on 100 patients with adnexal masses presenting to Department of Obstetrics and Gynecology at Kamla Raja Hospital, G.R.M.C, Gwalior from February 2015 to August 2016. Firstly, the cases were studied by ultrasonography then intraoperatively and simultaneous sampling for HPE done. The study included women with clinical symptoms of pain abdomen/ discomfort, bleeding per vaginum, abdominal mass was subjected to ultrasonography, diagnosed with adnexal mass. 100 indicated patients were taken for surgery and intraoperative tissue and fluid samples were taken and sent for HPE.

Results: No discordance found regarding laterality of adnexal masses between ultrasonographical findings and surgical findings. $69 \%$ cases were devoid of any septation/locules/nodules. Most common pathology found to be ectopic pregnancy. Most common benign ovarian mass encountered was serous cystadenoma (31.1\%) and malignant mass was serous adenocarcinoma (12.7\%). Apart from 13 malignant adnexal masses, 2 adnexal masses had malignant changes found on histopathological examination. 11 cases were found to be of advanced stage on surgical findings, which then confirmed by HPE.

Conclusions: There is positive correlation between ultrasonographical and surgerical evaluation of adnexal masses. Correlation of the lesion's location and appearance at imaging with the surgical findings will aid in the detection of potential pathology reporting errors.
\end{abstract}

Keywords: Adnexal masses, HPE, Surgical, Ultrasonography

\section{INTRODUCTION}

Adnexal masses are one of the most common pathologies among women of all age groups. They can be classified in ovarian, paraovarian or tubal. ${ }^{1}$ Ovarian tumors, alone, represent two thirds of these cases and malignant ovarian tumors are the fourth most common cause of death in women. $^{2}$ Approximately $4-24 \%$ of adnexal masses in premenopausal women and $39-63 \%$ in postmenopausal women are malignant. ${ }^{3}$ It has been estimated that $5 \%$ to $10 \%$ of women will undergo a surgical procedure owing to a suspected ovarian mass during their lifetime, and $13 \%$ to $21 \%$ of these women will suffer from malignancy. ${ }^{4}$

These adnexal masses can vary from benign masses like functional cysts to life threatening ectopic pregnancies to malignant masses like ovarian cancer. ${ }^{5}$ Suspected ovarian 
neoplasm is a common problem in women of all ages and ectopic pregnancy in women of reproductive age group. Women have a 5-10 percent risk of requiring surgery, and those who underwent surgery have 13 to 21 percent chances of being diagnosed with ovarian cancer. ${ }^{5}$

Determining the benign nature of the mass through imaging will not only save the patient from unnecessary surgery but also alleviate patient's worry. On the other hand, malignant masses and ectopic pregnancy need to be identified as early as possible so that the patient gets the appropriate treatment.

Ultrasonography being its wide availability, decreased costs, safety and simplicity of the examination and has been shown to be accurate for both detecting and characterizing adnexal mass, it is the modality of choice for imaging suspected adnexal masses.

Surgery serves two roles, both diagnostic and therapeutic. ${ }^{6}$ The diagnostic role of surgery enables: identifying the nature (benign or malignant) and location of the primary disease (ovarian, tubal, and colonic); if malignant, defining the areas to which the disease has spread (stage); providing information on other poor prognostic variables such as grade and histologic type.

The therapeutic role of surgery provides the opportunity for optimal debulking, granting a survival advantage. Accordingly, for many cases, surgical excision of the cyst serves as the definitive diagnostic tool. The diagnostic credibility of surgery is definitely better than radiology. Surgery followed by histopathological examination is the gold standard in diagnosing adnexal mass.

\section{METHODS}

A prospective study done on 100 women with adnexal masses presenting to Department of Obstetrics and Gynecology at Kamla Raja Hospital, G.R. Medical College and J.A. Group of Hospitals, Gwalior (M.P, India) from February 2015 to August 2016. All women with complaints of abdominal masses, abdominal pain, menstrual irregularities, bleeding per vaginum and/ or dysmenorrhea were subjected to Transvaginal sonography/Transabdominal sonography in the Department of Radiology at G.R. Medical College and J.A. Group of Hospitals, Gwalior. The study included women diagnosed with adnexal masses by ultrasonography. Patients with uterine leiomyoma, adenomyosis and patient unfit for surgery due to medical illnesses were excluded from the study. In the study, during ultrasonography echogenicity, laterality, site of origin and location and physical features of adnexal masses and presence of ascites and fluid in pouch of douglas were noted.

All the 100 women who were provisionally diagnosed with adnexal masses by clinical examinations and ultrasonography; gynecological cases with pre-anesthetic fitness during routine hours and ectopic pregnancy cases during emergency hours, went through surgical procedure; laparatomy.

The surgical procedures were performed by senior gynecologists of the department who had passed their residency program of 3 years with MS degree and have more than 10 years of experience in the field.

In the study, during surgery laterality, site of origin and location and physical features of adnexal masses; presence of hemoperitoneum, ascites and metastases were identified. Intraoperatively required biopsy and specimens also taken and sent for histopathological examination to the Department of Pathology, GRMC, Gwalior.

Comparative study was done among usg findings and surgical findings for the accuracy of the diagnosis of the adnexal masses.

Final diagnosis was made on histopathological reports after surgical removal of the masses.

\section{RESULTS}

Out of 100 cases only $8 \%$ cases comprised of bilateral adnexal mass. There was no discordance found regarding laterality of adnexal masses between ultrasonographical findings and surgical findings.

Table 1: Distribution according to laterality of adnexal mass (on USG and surgical findings).

\begin{tabular}{|lll|}
\hline Laterality & No. of patients & Percentage \\
\hline Right & 54 & 54 \\
\hline Left & 38 & 38 \\
\hline Bilateral & 8 & 8 \\
\hline
\end{tabular}

$69 \%$ cases were devoid of any septation/locules/nodules. Hemoperitoneum was present in cases of ruptured ectopic pregnancies, endometrioma and ruptured corpus luteum. Cases with ascites were found to be malignant.

Table 2: Distribution according to presence of septations /nodules /locules in the adnexal masses (ultrasonographical findings).

\begin{tabular}{|lll|} 
& No. of patients & Percentage \\
\hline Septation & 15 & 15 \\
\hline Nodules & 1 & 1 \\
\hline Locules & 15 & 15 \\
\hline
\end{tabular}

Out of 56 cases of ruptured ectopic pregnancy, 1 case coexisted with same sided hemorrhagic cyst, 3 cases with contra lateral functional ovarian cyst, 1 case with ruptured luteal cyst, 1 case with same side functional cyst and 1 case associated with findings (tubercular beads) suggestive of tuberculosis. Highest incidence of tubal 
pregnancy i.e. $37 \%$ found followed by fimbrial pregnancy.

Table 3: Distribution according to presence of fluid in POD, ascites in USG findings.

\begin{tabular}{|lll|} 
& No. of patients & Percentage \\
\hline Fluid in POD & 68 & 68 \\
\hline Ascites & 13 & 13 \\
\hline
\end{tabular}

Table 4: Distribution according to presence of hemoperitoneum, ascites and metastases in surgical findings.

\begin{tabular}{|lll|} 
& No. of patients & Percentage \\
\hline Hemoperitoneum & 59 & 59 \\
\hline Ascites & 13 & 13 \\
\hline Metastases & 11 & 11 \\
\hline
\end{tabular}

In this study, due to simultaneous occurrence of more than one adnexal mass in some patients, the total percentage is more than 100 .

Table 5: Distribution of patients according to origin of adnexal masses on USG.

\begin{tabular}{|lll|}
\hline Origin of mass & $\begin{array}{l}\text { No. of } \\
\text { patients }\end{array}$ & Percentage \\
\hline Adnexa (Tuboovarian mass) & 31 & 31 \\
\hline Ovarian & 10 & 10 \\
\hline Ectopic pregnancy & 56 & 56 \\
\hline Paraovarian & 1 & 1 \\
\hline Others & 2 & 2 \\
\hline
\end{tabular}

Table 6: Distribution according to provisional diagnosis based on surgical findings.

\begin{tabular}{|lll|}
\hline & $\begin{array}{l}\text { No. of } \\
\text { patients }\end{array}$ & Percentage \\
\hline Ruptured ectopic pregnancy & 50 & 50 \\
\hline $\begin{array}{l}\text { Ruptured ectopic pregnancy } \\
\text { with ovarian cyst }\end{array}$ & 6 & 6 \\
\hline Ovarian cyst & 18 & 18 \\
\hline Ovarian carcinoma & 11 & 11 \\
\hline Dermoid cyst & 9 & 9 \\
\hline Chocolate cyst & 3 & 3 \\
\hline Others & 2 & 2 \\
\hline Broad ligament fibroid & 1 & 1 \\
\hline
\end{tabular}

Most common pathology as adnexal mass diagnosed histopatholgically was ectopic pregnancy (49.55\%) followed by serous cystadenoma (13.27\%) then functional ovarian cyst $(7.07 \%)$ and then dermoid cyst.

Apart from 13 malignant adnexal masses, 2 adnexal masses had malignant changes found on histopathological examination. 11 cases were found to be of advanced stage on surgical findings, which then confirmed by HPE.
Table 7: Distribution based on surgically and histopathologically confirmed sites of ectopic pregnancy.

\begin{tabular}{|ll|}
\hline Ectopic pregnancy & No. of patients \\
\hline Tubal & 21 \\
\hline Ampullary & 9 \\
\hline Fimbrial & 15 \\
\hline Ovarian & 5 \\
\hline Infundibular & 3 \\
\hline Isthmus & 1 \\
\hline Cornual & 2 \\
\hline
\end{tabular}

In this study, the age of women with adnexal masses was in range of 54 years $(\min =16, \max =70)$, with an average of 31.40 years (SD- 9.975$)$ years.

Table 8: Distribution according to diagnosis based on histopathological examination reports

\begin{tabular}{|lll|}
\hline & $\begin{array}{l}\text { No. of } \\
\text { patients }\end{array}$ & Percentage \\
\hline Ectopic pregnancy & 56 & 49.55 \\
\hline Hemorrhagic cyst & 1 & 0.88 \\
\hline Functional ovarian cyst & 8 & 7.07 \\
\hline Corpus luteum cyst & 2 & 1.76 \\
\hline Endometrioma & 3 & 2.65 \\
\hline Dermoid cyst & 7 & 6.19 \\
\hline $\begin{array}{l}\text { Dermoid cyst with } \\
\text { malignant changes }\end{array}$ & 2 & 1.76 \\
\hline Serous cystadenoma & 15 & 13.27 \\
\hline Serous adenocarcinoma & 6 & 5.30 \\
\hline Mucinous cystadenoma & 3 & 2.65 \\
\hline $\begin{array}{l}\text { Tuboovarian } \\
\text { tuberculosis complex }\end{array}$ & 2 & 1.76 \\
\hline Ligamentous myoma & 1 & 0.88 \\
\hline Dysgerminoma & 1 & 0.88 \\
\hline Yolk sac carcinoma & 1 & 0.88 \\
\hline Tubercular findings & 5 & 4.42 \\
\hline
\end{tabular}

Table 9: Comparison between ultrasonographical findings and surgical findings and HPE reports.

\begin{tabular}{|llll|}
\hline & USG & Surgical & HIPE \\
\hline Benign & 87 & 87 & 85 \\
\hline Malignant & 13 & 13 & 15 \\
\hline
\end{tabular}

\section{DISCUSSION}

All the 100 patients who were provisionally diagnosed with adnexal masses by clinical examinations and ultrasonography went through surgical procedure; laparatomy. Final diagnosis was made by confirmation of histopathological reports after surgical removal of the masses.

Sensitivity and specificity calculations were not possible as true negatives and false negatives in present study were not available. 
In this study no discordance found regarding laterality of adnexal masses between ultrasonographical findings and surgical findings.

In 68 cases, fluid in pouch of Douglas was found in USG, of which 59 cases had hemoperitoneum on surgical findings; in these cases, 56 cases were of ectopic pregnancy, 2 were cases of endometrioma and 1 case of ruptured corpus luteum. And in 13 cases where ascites was diagnosed were found to be of malignant origin, histopathologically. Of these 13 cases of adnexal mass with ascites, 11 cases had metastases to adjoining and distant organs suggesting advanced stage of carcinoma.

Out of 100 cases, 56\% cases were of ectopic pregnancy followed by $31 \%$ cases of tubo-ovarian mass followed by $10 \%$ cases of ovarian origin. In ultrasonographical findings there were significantly more often registered ectopic pregnancy (n-56) than other adnexal masses in all the investigated women. Adnexal masses significantly rarer in the menopausal women.

Out of 56 cases of ruptured ectopic pregnancy, 1 case coexisted with same sided hemorrhagic cyst, 3 case with contra lateral functional ovarian cyst, 1 case with ruptured luteal cyst, 1 case with same side functional cyst and 1 case associated with findings (tubercular beads) suggestive of tuberculosis. The exact location of ectopic pregnancy was not given in none of the cases by ultrasonogarphy but was diagnosed only on surgical exploration and confirmed by histopathological examination reports. Highest incidence of tubal pregnancy i.e. $37 \%$ was found followed by fimbrial pregnancy which is in concordance with the Data from Callen, Bouyer, where maximum percentage was found of tubal pregnancy $(21 \%)$ followed by fimbrial prgnancy. ${ }^{7}$ The 56 cases of ruptured ectopic pregnancy, only one case was given unruptured in usg where ectopic sac was seen as thick walled complex cystic adnexal mass demostrated fetal pole with decidual reaction in the uterus and fluid in the Pouch of Douglas( in usg). Ectopic sac was detected reliably in 46 to $71 \%$ of reported case of tubal implantation, if the tube was unruptured. ${ }^{8} \mathrm{Al}$ Shukri et al, reported that out of 57 cases operated for adnexal masses in emergency, the most common pathology was teratoma $26 \%$ followed by corpus luteal hemorrhage (16\%) and endometriosis (14\%). ${ }^{9}$ But in present study 56 cases were operated in emergency and all were cases of ruptured ectopic pregnancy. All other masses were operated in routine, of which most common pathology was serous cystadenoma (15) followed by functional ovarian cyst then dermoid cyst. ${ }^{8,9}$

Tubo-ovarian abscesses are seen as complex, nonspecific adnexal masses. There are 2 tubo-ovarian abscesses out of 33 tubo -ovarian mass lesions encountered in present study. One young patient with primary infertilty and pelvic discomfort and a palpable mass per vaginum revealed a complex mass with irregularity of the bladder and the uterine wall. The lesion was thought to be malignant but found to be tubercular tubo-ovarian abscess on surgical exploration. In young patient with infertility an inflammatory benign pathology should have been considered first. Present study is similar to the study of Walsh et al. ${ }^{10}$ The author reviewed 204 gynecological masses. It was mentioned that 8 masses were described as thick walled with necrotic centre to be abscesses which later on proved to be malignant neoplasm. According to Walsh et al. ${ }^{10}$ tubo-ovarian abscesses should have thick walls with at least one cystic component associated with loss of tissue planes. In present study, 5 out of 100 patients with adnexal masses were found to be tuberculosis which is similar to the study.

In this study out of 15 malignant cases (confirmed on HPE), all the 15 cases had septations or locules. In 14 cases, the masses were of size $>10 \mathrm{~cm}$. In 1 case of Yolk cell carcinoma, the mass was size of $6 * 6 \mathrm{~cm}$ in surgical findings and $5 * 5 \mathrm{~cm}$ in US finding. In a study by Modesitt et al of postmenopausal women, no cancers were detected in 3259 simple ovarian cysts less than 10 cm. ${ }^{11}$ The authors of that study estimated the risk of malignancy in simple cysts as less than 0.1\%.11 This study is similar to present study, where out of 15 malignant cases (confirmed on HPE), in 14 cases, the masses were of size $>10 \mathrm{~cm}$. In 1 case of Yolk cell carcinoma, the mass was size of $6 * 6 \mathrm{~cm}$ in surgical findings and $5 * 5 \mathrm{~cm}$ in ultrasonographical findings.

Age of the patients we encountered ranged between 16 years to 70 years with the mean age of 31 years. However, $29 \%$ cases were in the age group of 26-30 years and none from age group 61-65 years evidence from Table 10.

Table 10: Age incidence.

\begin{tabular}{|lll|}
\hline Age (years) & No. of patients & Percentage \\
\hline $16-20$ & 7 & 7 \\
\hline $21-25$ & 21 & 21 \\
\hline $26-30$ & 29 & 29 \\
\hline $30-35$ & 23 & 23 \\
\hline $36-40$ & 6 & 6 \\
\hline $41-45$ & 5 & 5 \\
\hline $46-50$ & 3 & 3 \\
\hline $51-55$ & 2 & 2 \\
\hline $56-60$ & 3 & 3 \\
\hline $61-65$ & 0 & 0 \\
\hline $66-70$ & 1 & 1 \\
\hline
\end{tabular}

Out of that number $91 \%$ patients were still in their reproductive period, while $9 \%$ women were already in menopause. The age of the women with adnexal masses was in range of 54 years $(\min =16, \max =70)$, with an average of 31.40 (SD- 9.975) years. The incidence of adnexal mass was more in the $21-45$ years with the maximum in 21-35 years age group. According to a literature one of the factors which could predict the stage and survival of patients as well as the tumors recurrence 
is their age. ${ }^{12}$ Older patients are under higher risk for worse outcome. These data correspond with the results of present study which has proven that patients with malignant tumors are significantly older than those who had benign masses. ${ }^{13,14}$

\section{CONCLUSION}

Correlation of the lesion location and appearance at imaging with the surgical findings will aid in the detection of potential pathology reporting errors. Ovarian masses having fluid with internal echoes favoured malignancy while clear fluid favoured benignity. In conclusion, imaging, surgical, and histologic correlation is important in assessing the diagnostic accuracy of imaging of adnexal masses. The study has positive correlation between ultrasonographical and surgical evaluation of adnexal masses.

Funding: No funding sources Conflict of interest: None declared

Ethical approval: The study was approved by the Institutional Ethics Committee

\section{REFERENCES}

1. Guerriero S, Ajossa S, Garau N, Paoletti AM, Mais V. B-mode and power Doppler ultrasound in adnexal masses. J Don S J Ultr Obs Gyn. 2009;3(1):31-40.

2. Poveda A. Ovarian cancer: is the news good enough? Int J Gynecol Cancer. 2005;15(3):298-306.

3. Myers ER, Bastian LA, Havrilesky LJ, Kulasingam SL, Terplan MS, Cline KE et al. Management of adnexal mass. Evid Rep Technol Assess. 2006;5(130):1-14.

4. Pejovic T, Nezhat F. Laparoscopic management of adnexal masses: the opportunities and the risks. Ann NY Acad Sci.2001;943(1):255-268.

5. Graham L, ACOG Releases Guidelines on managmaent of adnexal masses. Am Fam Physician. 2008;77(9):1320-3.
6. Elit L. Surgical management of an adnexal mass suspicious for malignancy. Journal SOGC. 2000;22(11):964-8.

7. Callen PW Ultrasonography in Obstetrics and Gynecology, 4th ed. Philadelphia, WB Saunders, 2000, p 919.

8. Nyberg D. Ectopic pregnancy. In Nyberg NA, Hill LM, Bohm-Velez M, et al (Eds): Transvaginal sonography. St Louis: Mosby Year Book. 1992:105.

9. Shukri Al M, Mathew M, Ghafri WA. A clinicopathological study of women with adnexal masses presenting with acute symptoms.2014;4(2):286-288.

10. Walsh JW, Taylor KJ, Wasson JF, Schwartz PE, Rosenfield AT. Gray scale ultrasound in 204 proved gynaecologic masses. Accuracy and specific diagnostic criteria. Radiol. 1979;130;391-7.

11. Modesitt SC, Pavlik EJ, Ueland FR, DePriest PD, Kryscio RJ, van Nagell Jr JR. Risk of malignancy in unilocular ovarian cystic tumors less than 10 centimeters in diameter. Obstet Gynecol. 2003;102(3):594-9.

12. Tworoger SS, Gertig DM, Gates MA, Hecht JL, Hankinson SE. Caffeine, alcohol, smoking, and the risk of incident epithelial ovarian cancer. Cancer 2008;112(5):1169-77.

13. Chan JK, Tian C, Monk BJ, Herzog T, Kapp DS, Bell J, et al. Prognostic factors for high-risk earlystage epithelial ovarian cancer: a Gynecologic Oncology Group study. Cancer 2008;112(10):220210.

14. Kazerouni N, Greene MH, Lacey JV Jr, Mink PJ, Schairer C. Family history of breast cancer as a risk factor for ovarian cancer in a prospective study. Cancer. 2006;107(5):1075-83.

Cite this article as: Tripathi $\mathrm{U}$, Munda G.

Study of correlation of ultrasonography with surgical evaluation of adnexal masses: a prospective study. Int J Reprod Contracept Obstet Gynecol 2018;7:421822. 